
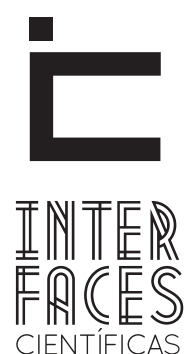

EDUCAÇÃO

ISSN IMPRESSO 2316-333X

ISSN ELETRÔNICO 2316-3828

ARTIGOS DE DEMANDA

\title{
CONTRIBUIÇÕES DE GRANDES PENSADORES DA HISTÓRIA DA EDUCAÇÃO PARA O DESENVOLVIMENTO DO HOMEM EM SOCIEDADE
}

Laudelino Luiz Castro Tanajura ${ }^{1}$

Simone Silveira Amorim ${ }^{3}$
Cristiano de Jesus Ferronato ${ }^{2}$

\section{RESUMO}

A educação do homem e o seu desenvolvimento. Foi para Galvão (2010); Comenius (2002); Le Goff (1994); Rousseau (1979); Dewey (1965), etc. uma preocupação e ao mesmo tempo um objeto de incessante estudo, o que levou esses e outros grandes pensadores do desenvolvimento humano a dedicarem suas vidas a compreender e explicar como se da o conhecimento e o processo de educação ao longo do tempo. Nesse contexto, destacamos as experiências dos sujeitos, o papel da memória e a dicotomia (sujeito e objeto) no desenvolvimento do homem individualmente e em sociedade. Por meio da pesquisa bibliográfica, objetivou-se, considerando os diferentes contextos históricos, apontar as diferentes visões dos autores sobre a importância da educação para o desenvolvimento do conhecimento humano nos diversos campos do saber.

\section{PALAVRAS-CHAVE}

História. Sociedade. Conhecimento. Educação. Desenvolvimento. 


\section{ABSTRACT}

The education of man and its development. Was to Galvão (2010); Comenius (2002); Le Goff (1994); Rousseau (1979); Dewey (1965), etc. a concern while a ceaseless study object, which led these and other great thinkers of human development to devote their lives to understand and explain how the knowledge and the education process over time. In this context, we highlight the experiences of the subjects, the role of memory and the dichotomy (subject and object) in the development of man individually and in society.
Through literature review aimed to considering the different historical contexts, pointing out the different views of the authors on the importance of education for the development of human knowledge in the various fields of knowledge.

\section{KEYWORDS}

History. Society. Knowledge. Education. Development.

\section{RESUMEN}

La educación del hombre y su desarrollo, fue para Galvão (2010); Comenius (2002); Le Goff (1994); Rousseau (1979); Dewey (1965), etc., una preocupación, y a la vez, un objeto de estudio incesante, lo que llevó estos y otros grandes pensadores del desarrollo humano a dedicar su vida a entender y a explicar, como si dio el proceso de conocimiento y la educación con el tiempo. En este contexto, se destacan las experiencias de los sujetos, el papel de la memoria y la dicotomía (sujeto y objeto) en el desarrollo del hombre individual y en la sociedad. A través de la literatura, a fin de considerar los diferentes contextos históricos, señalando las diferentes opiniones de los autores acerca de la importancia de la educación para el desarrollo del conocimiento humano en los diversos campos del saber.

\section{PALABRAS CLAVE}

Historia. Sociedad. Conocimiento. Educación. Desarrollo 


\section{INTRODUÇ̃̃O}

Muitas são as interrogações a respeito da educação. Questões que o ser humano consciente quer responder, mais que nem sempre encontra respostas que contemplem plenamente o entendimento. Pesquisadores e humanistas concordam que a educação, assim como os valores estão atrelados ao conhecimento e ao desenvolvimento das sociedades, concordam ainda que a educação não cria o homem e sim o ajuda a criar a si mesmo e a desenvolver sua própria cultura.

Muito do que ocorre no universo da educação ainda é pouco conhecido pelos pesquisadores - e mesmo pelos professores. 0 contato com o que é novo pode possibilitar, por similitude e diferença, uma maior compreensão de si e da própria cultura. (GALVÃO e LOPES, 2010, p. 11).

Existe a necessidade de se entender que aprender é um processo complexo, onde o ser humano deve ser o sujeito ativo na construção do conhecimento, e que este somente se dá a partir da ação do sujeito sobre a realidade. 0 conhecimento é o principal fator de inovação disponível ao ser humano. O conhecimento não é constituído de verdades estáticas, mas sim de um processo dinâmico, que acompanha a vida humana e não constitui em mera cópia do mundo exterior. É nesse processo que segundo Le Goff (1994) deve-se observar aspectos do estudo da memória, de traços e problemas da memória histórica e da memória social, as noções de aprendizagem, as fases de aquisição da memória, e os sistemas de educação da memória que existiram nas várias sociedades e em diferentes épocas.

Nesse sentido o conhecimento serve de guia para ação. Ele emerge da educação e da interação social acumuladas na memória e tem como característica fundamental o fato de poder ser manifestado e ser transferido por intermédio da comunicação. Assim a capacidade de aprender, de desenvolver novos padrões da interpretação e de ação, depende da diversidade e da natureza do conhecimento acumulados na memória. “A memória, como propriedade de conservar certas informações, remete- -nos em primeiro lugar a um conjunto de funções psíquicas, graças às quais o homem pode atualizar impressões ou informações passadas, ou que ele representa como passadas” (LE GOFF, 1994, p. 423). Fica claro, na visão do autor, que o uso da memória é indissociável ao desenvolvimento da educação e consequentemente a disseminação do conhecimento, que comina com o progresso do individual do homem e coletivo das sociedades em geral.

\section{RELAÇÃO HOMEM E CONHECIMENTO}

Todos os homens adquirem e desenvolvem seu conhecimento de acordo com as condições do meio natural e social em que vivem e dessas relações diretas entre os indivíduos nasce a necessidade de educar-se para compreender melhor o mundo. Sustentando essa visão Aristóteles (1969) diz que "Todos os homens têm, por natureza, o desejo de conhecer”. Nessa perspectiva a questão da história da educação e do conhecimento é um tema inerente às especulações filosóficas, da antiguidade até os dias atuais. Desde então existem uma diversidade de teorias as quais os filósofos sempre se preocuparam, sendo difícil constatar uma coincidência de pensamento e conceitos entre eles.

Dentre os principais princípios da teoria do conhecimento e da história da educação podemos citar as fontes primeiras do conhecimento e sua relação com os processos que se transformam em juízos e o jeito de considerar a atividade do sujeito frente ao objeto a ser conhecido. A esse respeito Galvão e Lopes (2010, p. 11) comentam que "Muito do que ocorre no universo da educação ainda é pouco conhecido pelos pesquisadores - e mesmo pelos professores. 0 contato com o que é novo pode possibilitar, por similitude e diferença, uma maior compreensão de si e da própria cultura”. Para que a relação homem conhecimento aconteça é necessário considerar o que esse contato com o novo propicia como experiência útil na vida e depois no contexto educativo em que se insere o sujeito e o objeto. 
Segundo a filosofia a relação homem conhecimento nasceu da necessidade em descobrir e entender o mundo em que vive ou, no dizer de Aristótelos (1969), "do espanto em relação àquilo que não conhecemos". Dessa maneira, a filosofia busca entender o próprio homem, ou seja, o ser, bem como as coisas que nos rodeiam, a natureza humana e não humana, sua criação e sua transformação.

Para, existir conhecimento é necessário que haja a relação entre dois elementos básicos: um sujeito conhecedor (mente) e um objeto conhecido (a realidade). Só haverá conhecimento se o sujeito conseguir apreender o objeto, isto é, representá-lo mentalmente. Jonh Locke (1998, p. 21) afirma que:

Raramente há alguém tão instável e superficial em seu entendimento que não tenha reverenciado algumas proposições, que são para ele os princípios sobre os quais fundamenta seus raciocínios, e pelos quais julga a verdade e falsidade, o certo e o errado.

No campo do conhecimento defrontam-se consciência e objeto, sujeito e objetivo. 0 conhecimento aparece como resultado da relação entre esses dois elementos. Nessa relação, sujeito e objeto, permanecem eternamente separados, o dualismo do sujeito e do objeto pertence à essência do conhecimento. Segundo John Locke (1988) Isso nos dá o entendimento que nos faz ver e perceber todas as outras coisas permite situá-lo à distância e fazê-lo seu próprio objeto, possibilita lançar sobre nossas mentes, todo o conhecimento que possamos adquirir de nosso entendimento, orientar nossos pensamentos na busca de outras coisas, considerar as faculdades discernentes do homem, e como elas são empregadas sobre os objetos que lhes dizem respeito. Constitui nessa visão o reconhecimento e ao mesmo tempo o respeito à individualidade do sujeito.

Refletindo sobre os conceitos da teoria do conhecimento e da história da educação, podemos concluir que a relação do homem com o conhecimento faz parte de uma argumentação filosófica na construção do saber, em que segundo Valdemarin e outros autores (2006, p. 186): "[...] a teoria não tem significado senão quando crivada pela experiência, que por sua vez é capaz de mobilizar conhecimento intelectual para produzir saber". O dualismo (conhecimento e educação) torna-se dessa forma indissociável ao desenvolvimento do homem, enquanto ser individual e enquanto membro de um grupo social, e ao mesmo tempo nos faz refletir sobre os valores que fazem parte do conhecimento, da cultura e da educação, estruturados e aceitos pelas sociedades através dos tempos.

Na relação homem e conhecimento visualizam-se as influências das condições do meio natural e não natural, e a necessidade da educação para intermediar o compreender do mundo, as contribuições que o contato com o novo pode possibilitar e a atividade do sujeito frente ao objeto a ser conhecido. Nessa relação sujeito e objeto, em que o dualismo permanece sempre separado, o conhecimento representa as faculdades discernentes do homem.

\section{CONHECIMENTO E SUA TRAJETÓRIA NA SOCIEDADE NA VISÃO DE ALGUNS TEÓRICOS}

Os processos de escolarização para as crianças pequenas, ao longo da história, apresentam pequenos avanços durante um período grande de tempo e exigem esforços de ordens política, social, filosófica e pedagógica para então compreendê-las.

Na Idade Média, a criança não era reconhecida como um ser social era apenas um ser humano ingênuo inocente ou ainda incompleto, uma miniatura do adulto. Acreditava-se que ela necessitava apenas do caráter assistencialista, dispensava-se qualquer tratamento pedagógico voltado para essa faixa etária e a infância era tida como fase de transição para a vida adulta e para as relações sociais. Seria simplista considerar a ausência do sentimento da infância ao longo 
da história, porém é frutífero compreender as diversas concepções existentes, uma vez que as mudanças ocorridas fazem surgir à necessidade de aceitação desta categoria denominada de "primeira infância".

No século XII a infância não aparecia na arte medieval, representação muito utilizada pela sociedade nessa época, e para a diferença entre a criança e o adulto era apenas o seu tamanho. Pode-se dizer que a descoberta da infância ocorre no século XIII, influenciada pela história da arte e ligada à igreja, porém somente evolui de forma significativa a partir do final do século XVI e XVII.

Nos séculos XVII e XVIII, nomes significativos do pensamento pedagógico, como Comenius (15921670), Rousseau (1712-1778), Pestalozzi (1746-1827) e Froebel (1782-1852) surgem com uma nova ideia ou "sentimento de infância" que visa auxiliar este grupo etário a conquistar um lugar enquanto categoria social.

Nessa visão Comenius propõem uma escola perfeita que ainda não foi alcançada, em que as crianças aprendam com um método mais fácil, para se sentirem seduzidas por ele, para que encontrem nos estudos um prazer não menor do que o que sentem ao brincar. 0 autor acredita que a escola possa ser reformada e methorada, e para isso propõe uma organização escolar.

[...] a arte universal de ensinar tudo a todos, ou seja, o modo certo e excelente para criar em todas as comunidades, cidades ou vilarejos de qualquer reino cristão escolas tais que a juventude de dois sexos, sem excluir ninguém, possa receber uma formação em letras, ser aprimorada nos costumes, educada para a piedade e, assim, nos anos da primeira juventude, receba a instrução sobre tudo o que é da vida presente e futura, de maneira sintética, agradável e sólida. (COMENIUS, 2002, p. 11).

0 autor defende, ainda, que desenvolvida a atividade dos membros e dos sentidos, o menino começa, espontaneamente, a exteriorizar seu interior, e entra dessa forma no início do seu desenvolvimento. Acredita que entre os diferentes períodos do crescimento e da educação do homem, não se pode estabelecer nenhuma ordem rigorosa de pré-relação, pois todos são igualmente importantes em seu lugar e tempo.

Froebel (1782-1852), muito bem entendeu essa visão de Comenius (1592-1670), ao afirmar que: "As primeiras manifestações da criança, sua conservação e cuidado, devem constituir o ponto de partida da primeira educação e a base de todo posterior desenvolvimento, aperfeiçoamento e atividade na vida" (FROEBEL, 2001, p. 33).

Na concepção de Froebel (2001), era preciso exteriorizar o interior e interiorizar o exterior, era preciso unificá-los, encontrar uma maneira de relacionar os objetos com os seus opostos, de considerar e não desvincular a vida do menino consigo mesmo, com os seus, com a natureza e com Deus, o que levaria pouco a pouco a criança à consciência de si mesma, e à futura reflexão sobre si mesma. 0 autor defendia a concepção de que "O mundo exterior e a criança se confundem: entre eles não se pode estabelecer uma distinção precisa" (FROBEL, 2001, p. 43)

\begin{abstract}
A principal inovação curricular introduzida na educação pré-escolar é o estudo da natureza, ciência considerada particularmente interessante para as crianças, que assume, com o método intuitivo, a posição de conteúdo escolar central pelo fato de possibilitar o conhecimento da forma, da força e do movimento. (VALDEMARIN, 1998, p. 71).
\end{abstract}

A educação pré-escolar na modernidade tem suas raízes no pensamento desses estudiosos, porém cabe ressaltar que as instituições pré-escolares são resultado das mudanças relacionadas à urbanização e a industrialização, visto que a organização social precisa acompanhar a transformação gradual e progressiva.

As ideias de Comenius, precursor de Rousseau e Froebel, nos remetem a relação estabelecida entre natureza e a criança a partir de sua obra Didactica Magna: 
Esta maneira de instruir e educar a juventude pode comparar-se também ao cultivo dos jardins. Com efeito, as criancinhas de seis anos, bem-exercitadas pelos cuidados dos pais e das amas, parecem semelhante às arvorezinhas que foram plantadas, enraizaram bem e começaram a lançar pequeninos ramos. (COMENIUS, 1957, p. 413).

Rousseau (1721-1778) complementa Comenius (1592-1670), pois além do destaque que ele dá a infância, ele sugere uma educação voltada aos sentidos, à liberdade e à naturalidade da criança quando em contato com a natureza, além de "exigir que a educação se orientasse para a criança e não para o conteúdo".

$\mathrm{Na}$ sequência, observamos Pestalozzi (17461827), o qual valoriza a primazia da percepção sensorial para a busca do conhecimento e a observação como recurso para alcançar a intuição, tanto para a escola primária, como para a educação infantil, era patente a presença da adoção do método intuitivo, e o programa para a educação infantil voltava-se para "lições de cousas", "canto", "recitação", "desenho", entre outros conteúdos.

Segundo Souza (2004, p. 172): “o debate sobre ensino intuitivo não é originário do século XX”.

O Jardim-de-infância era uma instituição digna de aplausos, pois representava um traço de união entre a família e a escola e cujos fins consistiam em desenvolver gradualmente as faculdades físicas, morais e intelectuais da criança, sem a preocupação dos livros e tarefas fastidiosas. (SOUZA, et al., 2004, p. 175).

A problemática decorre da questão sobre como ensinar, sobre a formação humana e a teoria do conhecimento que fundamenta o processo cognitivo do aluno e o conteúdo a ser ensinado e os valores formativos do processo de aprendizagem do aluno.

Já para Dewey (1965, p. 18) a educação é a forma, por meio da qual, transferimos ou captamos o conhecimento do meio externo por meio da experiência, "a [...] experiência reconstruída e reorganizada mental- mente no curso de sua elaboração". Nessa concepção a experiência alarga os conhecimentos, enriquece o nosso espirito cotidianamente, da significação mais profunda à vida, segundo o autor a própria vida social se perpetuava por intermédio da educação. "[...] integrando a aprendizagem obtida através de um exercício específico a isto destinado (escola), com a aprendizagem diretamente absorvida nas experiências sociais (vida). [...] é pela educação que a sociedade se perpetua" (DEWEY, 1965, p. 21).

Dewey tem sido considerado o maior pedagogo do século XX e o principal teórico da Escola Nova, do ponto de vista metodológico sua obra, tem como propósito delinear os aspectos gerais da Educação como o processo por meio do qual os grupos sociais mantém sua existência contínua. A educação é para ele o processo da renovação das significações da experiência, por meio da qual ocorre a transmissão acidental ou não, do contato ou trato ordinário entre os adultos e os mais jovens, e em parte intencionalmente instituída para operar a continuidade social. Este processo subentende a direção e o desenvolvimento dos indivíduos imaturos e do grupo em que eles vivem. Nessa ótica:

\begin{abstract}
Educar-se é crescer, não já no sentido puramente fisiológico, mas no sentido espiritual, no sentido humano, no sentido de uma vida cada vez mais larga, mais rica e mais bela, em um mundo cada vez mais adaptado, mais propício, mais benfazejo para o homem. [...] Processo de reconstrução e reorganização da experiência, pelo qual the percebemos mais agudamente o sentido, e com isso nos habilitamos a melhor dirigir o curso de nossas experiências futuras. (DEWEY, 1965, p. 17).
\end{abstract}

Na visão de Dewey (1965, p. 22), “[...] sendo a educação o resultado de uma interação, através da experiência, do organismo com o meio ambiente, a direção da atividade educativa é intrínseca ao próprio processo da atividade", ou seja, atividade educativa deve ser sempre entendida como uma libertação de forças e tendências e impulsos existentes no indivíduo, e por ele mesmos trabalhados e exercitados, e, "portanto dirigidos, porque sem direção eles não se poderiam exercitar" (DEWEY, 1965, p. 25), portanto o meio so- 
cial ou o meio escolar, se bem compreendidos, devem fornecer as condições pelas quais o indivíduo se liberte e realize a sua própria personalidade.

\section{CONCLUSÃO}

Ao analisarmos as interrogações a respeito do conhecimento e da sua influência sobre a educação, refletimos que essa não cria o homem, mais o ajuda a despertar e olhar para si mesmo como responsável pelo desenvolvimento da sua própria cultura, o quanto é importante para identificar o modo como em diferentes lugares e momentos uma realidade social é construída, pensada e dada a ler. Portanto, ao voltar-se para a vida social, o conhecimento pode tomar por objeto as formas e os motivos das suas representações e pensá-las como análise do trabalho de representação das classificações e das exclusões que constituem as configurações sociais e conceituais de um tempo ou de um espaço.

Entendemos que aprender é um processo complexo e que o homem deve ser o sujeito ativo na construção desse conhecimento, vimos que nesse sentido esse conhecimento deve servir de guia para a ação transformadora do indivíduo e da sociedade, que os métodos sintetizam todos os elementos próprios das tarefas educativas, uma vez que os procedimentos didáticos e os passos metódicos de suas práticas são traduções das teorias do conhecimento e da educação, aplicadas a uma ou mais faixas etárias e desenvolvidas sobre conteúdos sancionados socialmente e concretizados sobre objetos diversos. Reconhecemos que o uso da memória é indissociável ao desenvolvimento da educação e que essa memória favorece a disseminação do conhecimento nas diferentes esferas.

Os diálogos que as obras estudadas promovem com a pesquisa educacional produzida nos diferentes períodos, nos remete a outras leituras e estabelece alguns marcos importantes já conquistados, e aponta para perspectivas a serem enfrentadas pela educa- ção. Essas obras abordam o passado como origem de realizações e projetos em andamento, situa-nos num quadro de referencias que ganham compreensão e prosseguimento, nos dá a percepção de quem somos, e que sem educação e conhecimento os direitos dos indivíduos não estão protegidos e reconhecidos, não haveria democracia, ou seja, sociedade e cultura, história e educação, conhecimento e desenvolvimento.

\section{REFERÊNCIAS}

ARISTÓTELES - Metafísica. Liv. I, 11 Coimbra: Atlântida, 1969.

CHARTIER, Roger. A História Cultural: entre práticas e representações. Trad. Maria Manuela Galhardo. Lisboa: DIFEL; Rio de Janeiro: Bertrand, 1990.

COMENIUS, John. Didática Magna. São Paulo: Martins Fontes, 2002.

DEWEY, John. Vida e educação. Trad. Anísio S. Teixeira. São Paulo: Edições Melhoramentos, 1965.

FROEBEL, F. A Educação do Homem. Passo Fundo: UF, 2001.

GALVÃO, Ana Maria de Oliveira; LOPES, Eliane Marta Teixeira. Território plural: a pesquisa em história da educação. São Paulo: Ática, 2010.

LE GOFF, Jacques. História e Memória. Campinas: UNICAMP, 1994.

LOCKE, Jonh. Ensaio acerca do entendimento humano. São Paulo: Nova Cultura, 1988.

ROUSSEAU, Jean-Jacques. Emílio ou da Educação. Trad. Sérgio Milliet. São Paulo: Difel, 1979.

VALDEMARIN, Vera Teresa et al. 0 legado educacional do século XX no Brasil. Campinas, SP: Autores Associados, 2006. 
1. Mestrando em Educação pela Universidade Tiradentes CAPES/PROSUP/ PPDE/Unit/SE; Membro do Grupo de Pesquisa GPGFOP/UNIT/CNPq: na linha Iniciação à Pesquisa Científica na Educação Superior e Ensino Aprendizagem: E-mail: professorlaudelino@ig.com.br.

2. Doutor em Educação pela Universidade Federal da Paraíba. Professor do Programa de Pós Graduação em Educação da Universidade Tiradentes- PPED-UNIT. Coordenador do Grupo de Pesquisa em História da Educação no Nordeste

Recebido em: 14 de Fervereiro de 2014 Oitocentista GT-SE (GHENO-SE): E-mail: cristiano jesus@unit.br.

Avaliado em: 8 de Março de 2014

3. Doutora em Educação pela Universidade Federal de Sergipe. Professor do Programa de Pós Graduação em Educação da Universidade Tiradentes- PPED-

-UNIT. Membro do Grupo de Pesquisa em História da Educação no Nordeste Oitocentista GT-SE (GHENO): E-mail: simone_silveira@unit.br. 